LETTER TO THE EDITOR

\title{
Incidental kidney findings in ultrasonography: a hidden iceberg bottom for patients with chronic hepatitis B?
}

\author{
Dogan Z, Sarikaya M, Ergul B, Filik L \\ Ankara Research Hospital, Gastroenterology Division, Ankara, Turkey. leventfilik@yahoo.co.uk
}

Chronic hepatitis B (CHB) is successfully treated with antivirals such as tenofovir and entecavir. Those drugs are usually accepted as safe regarding nephrological aspect. Dose reduction is usually enough for the patients with decreased creatinine clearence. However, there is another issue that is ignored most of the times. This issue is the incidental abnormalities of kidneys in abdominal ultrasonography of patients with CHB.

As all know, patients with chronic active hepatitis B usually present with subtle clinical findings or nonspecific symptoms such as abdominal pain. Abdominal ultrasonography is a commonly performed investigation before antiviral treatment. Nevertheless ultrasonographic appearence of kidneys (renal cyst ,stone, etc) is usually ignored unless serum renal function tests or creatinine clearence are abnormal in daily practice.

Regarding this issue we retrospectively collected data of 109 patients who started to take entecavir or tenofovir in the last 2 years (Tab. 1). Renal ultrasonographic findings are shown in Table 2. Those data show that $25 \%$ of patients have an incidental and silent kidney lesion. We should remind that there is no data yet to reveal the fate of those silent renal lesions (cyst and stone) in course of $\mathrm{CHB}$ antiviral treatment that lasts for years. On the

Address for correspondence: L. Filik, MD, Ankara Research Hospital, Gastroenterology Clinic Ankara, 06600, Turkey.

Phone: +903125954272
Tab. 1. Demographic features.

\begin{tabular}{cccc}
\hline & Male & Female & $\mathrm{p}$ \\
$\mathrm{n}=63,57.8 \%$ & $\mathrm{n}=46,42.2 \%$ & \\
\hline Age (year) & $51.02 \pm 11.62$ & $50.91 \pm 9.64$ & $>0.96$ \\
\hline
\end{tabular}

Tab. 2. Kidney findings of patients with chronic hepatitis B.

\begin{tabular}{lcccc}
\hline Kidney Appearence & $\begin{array}{c}\text { Male } \\
\mathrm{n}=63\end{array}$ & $\begin{array}{c}\text { Female } \\
\mathrm{n}=46\end{array}$ & $\begin{array}{c}\text { Total } \\
\mathrm{n}=109\end{array}$ & $\mathrm{p}$ \\
\hline Normal & $45(71.4 \%)$ & $37(80.4 \%)$ & $82(75.2)$ & \\
Cyst only & $6(9.5 \%)$ & $7(15.2 \%)$ & $13(11.9 \%)$ & \\
Stones only & $3(4.8 \%)$ & $0(0.0 \%)$ & $3(2.8 \%)$ & $>0.174$ \\
Parenchymal disease & $6(9.5 \%)$ & $2(4.3 \%)$ & $8(7.3 \%)$ & \\
Both cysts and stones & $3(4.8 \%)$ & $0(0.0 \%)$ & $3(2.8 \%)$ & \\
\hline
\end{tabular}

other hand, symptoms might be misinterpreted by caretakers. For example, subtle abdominal pain from kidney may be regarded as pain due to hepatitis.

In conclusion, we underline herein that the caretakers (gastroenterologists, hepatologists, infectologists or internist etc.) of HBV patients should consider also silent renal diseases so that timely consultations with nephrologists and urologists are performed.

Received August 30, 2013. Accepted September 13, 2013. 